C.5

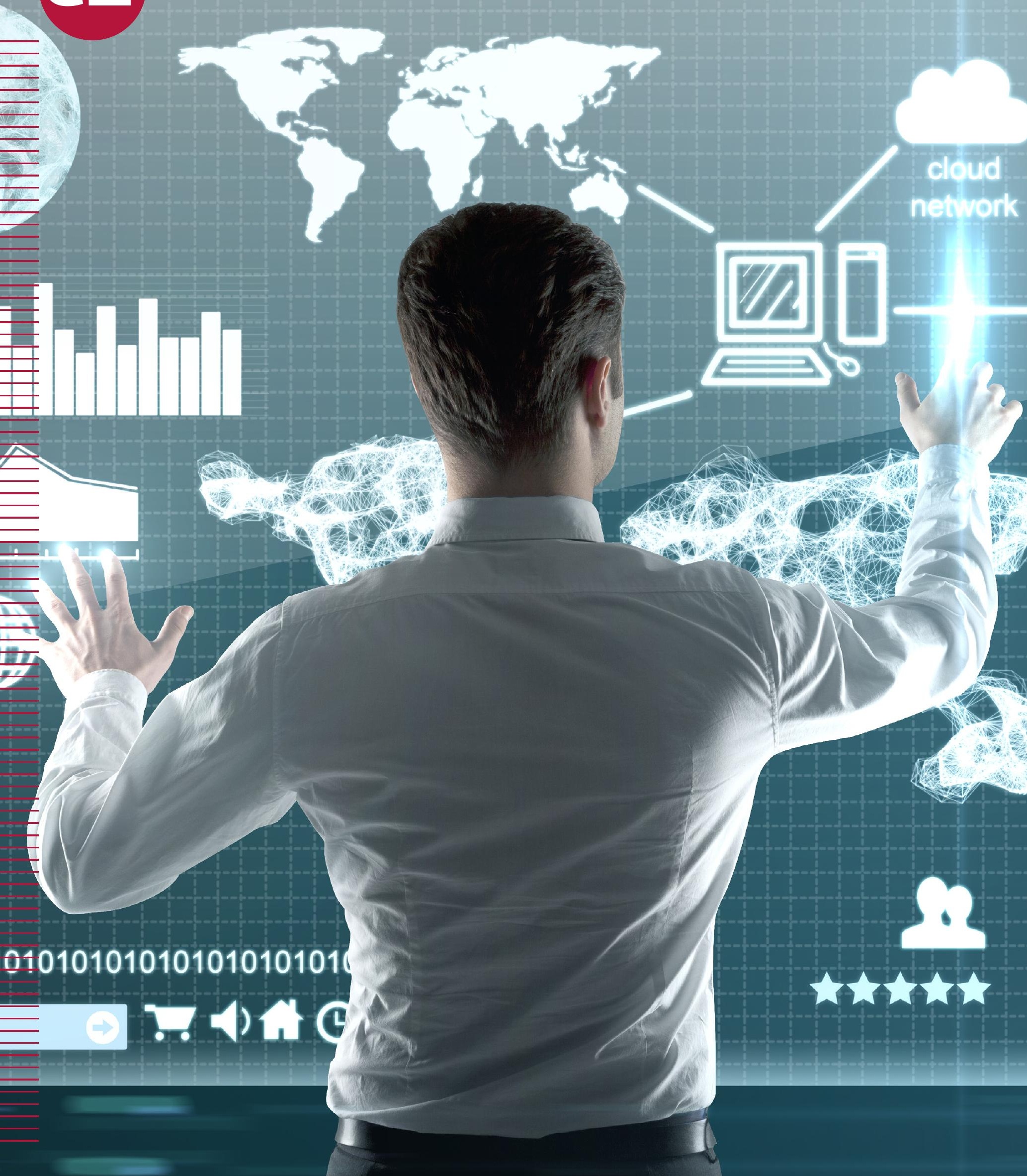




\section{OMNICHANNEL: \\ UMA GESTÃO \\ INTEGRADA}

| POR LEANDRO ANGOTTI GUISSONI

\section{Varejistas precisam desenvolver a capacidade de analisar os dados do consumidor de forma sincronizada e multicanal para ganhar vantagem competitiva.}

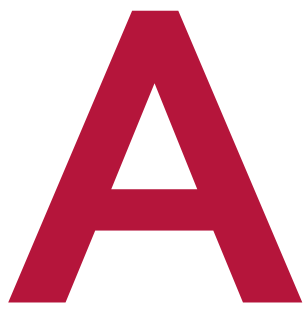

vanços tecnológicos vêm permitindo que consumidores utilizem diferentes dispositivos (celulares, smartphones, tablets, computadores) e canais (online, offline) durante a jornada de compras. Isso faz com que, hoje em dia, as empresas varejistas precisem estar preparadas para captar e analisar informações simultaneamente de todos esses pontos de contato e desenvolver estímulos de marketing ao cliente de forma integrada - uma perspectiva conhecida como omnichannel.

Para realizar essa complexa gestão omnichannel, as empresas estão tendo que melhorar sua capacidade analítica. Há cada vez mais recursos para aprimorar os processos de coleta, organização e classificação dos dados (data mining) gerados a partir do contato do consumidor com diferentes dispositivos e canais. A questão é: como usá-los?

\section{DESAFIOS DA GESTÃO OMNICHANNEL}

Executivos que trabalham no varejo se sentem pressionados por muitas mudanças e demandas. Eles têm sido cobrados para demonstrar o retorno de suas ações de maneira mais precisa do que antes em várias frentes: impacto no consumidor, ativos de marketing (como valor da marca e do cliente), posição financeira e posição de mercado.

Precisam usar esses dados para dar respostas a perguntas tais quais: como melhorar a experiência do consumidor nos diferentes pontos de contato com a marca? Quantos recursos devem ser alocados para cada atividade de marketing e comercial por loja, ponto de contato e mídia, região geográfica, tipos de produtos e segmentos de clientes?

De acordo com pesquisa da EKN, consultoria especializada em tecnologia para varejo, dois em cada cinco varejistas norte-americanos afirmam estar atrás da concorrência na forma como usam estrategicamente sua capacidade analítica. Isso ocorre porque: não conseguem administrar o volume de dados disponível de maneira agregada e alinhada aos objetivos do negócio; sentem-se confusos e com medo de errar diante de tantas opções tecnológicas; têm dificuldade de adotar uma real capacidade analítica, pois ao menos parte do corpo diretivo é desinformada ou tem uma visão ultrapassada a respeito 
do assunto; não contam com profissionais capacitados para a função; organizam seus times e recursos de forma desconectada da gestão omnichannel; e/ou ainda não treinaram os funcionários que tiveram suas funções transformadas e dependentes da análise de dados.

\section{BENEFÍCIOS DA GESTÃO OMNICHANNEL}

As mudanças para uma estratégia omnichannel têm desafiado o status quo da gestão de varejo, tradicionalmente baseada no julgamento dos executivos e do suporte fundamentado apenas em dados internos de loja para tomada de decisão. Mas, inevitavelmente, essa visão terá de mudar. A capacidade analítica apresenta possibilidades para que os varejistas desempenhem melhor e de maneira mais consistente as atividades entre os ambientes online e offline, cada dia mais sincronizados.

Uma pesquisa publicada neste ano na Harvard Business Review mostrou que, de 46 mil consumidores de uma grande rede varejista dos Estados Unidos, somente 7\% eram clientes exclusivamente do e-commerce e $20 \%$ frequentadores apenas das lojas físicas. Quase três quartos, ou 73\%, usavam múltiplos canais durante a jornada de compras. Esse grupo majoritário de clientes omnichannel gastou em média $4 \%$ mais cada vez que pôs os pés na loja durante o período do levantamento, e $10 \%$ mais online do que os clientes que usaram um único canal.

Outra questão é que quanto mais pontos de contato, maiores foram as compras. Aqueles que usaram quatro diferentes dispositivos ou canais gastaram $9 \%$ mais na loja do que os que usaram apenas um canal. Além disso, consumidores omnichannel foram mais fiéis: frequentaram $23 \%$ mais a loja do que os clientes exclusivos do mundo físico ou virtual.

\section{ANÁLISE NA GESTÃO OMNICHANNEL}

Com a integração das lojas à internet, redes sociais e aplicativos em vários dispositivos, é possível atingir um estágio mais avançado do customer analytics e obter maior retorno no negócio. O sistema conhecido como cookie tracking, por exemplo, permite monitorar a navegação de usuários a partir do endereço IP e relacioná-la com dados demográficos, geográficos e comportamentais de cada pessoa.

Os smartphones desempenham um importante papel na obtenção de dados, já que a navegação na internet nesses dispositivos móveis também pode ser monitorada pelo sistema de cookies. No Brasil, a penetração de smartphones aumentou de 7\% em 2011 para 43\% em 2016.

Nos Estados Unidos, onde a tecnologia é mais disseminada, empresas varejistas vêm usando com mais frequência informações de navegação em smartphones. A rede de lojas de departamento Kohl's utiliza um sistema chamado smartphone targeting. Quando os clientes entram na loja e conectam os seus smartphones no Wi-Fi, a empresa monitora sua localização e sua navegação em websites. Assim, envia ofertas personalizadas e gera maiores chances de conversão de vendas.

O exemplo da Kohl's ilustra o uso simultâneo de um ponto de contato online (smartphone) e offline (loja). A aplicação de níveis avançados de coleta e análise de dados em um contexto omnichannel permite ao varejista alcançar mais consistência nas atividades desempenhadas durante a interação com os consumidores. Torna-se viável saber mais sobre eles, otimizar o mix de produtos e oferecer promoções mais efetivas.

Além disso, é possível melhorar diversos outros aspectos da operação. Por exemplo, a capacidade analítica integrada abre caminho para capturar dados das operações online para decidir onde abrir lojas físicas, que produtos expor, quais níveis de serviço e de preço. Pode-se ainda reconfigurar a administração de estoques a partir da transformação dos pontos físicos em locais mais voltados para o fortalecimento da marca do que para a venda em si.

\section{COMO CRIAR CAPACIDADE ANALITICA}

Mas, para que essas estratégias funcionem, em um primeiro momento, varejistas devem objetivar obter e organizar dados sobre a interação do consumidor com cada ponto de contato. Precisam considerar a combinação dos seus dados internos com dados externos, incluindo informações individuais dos clientes. Por exemplo, podem cruzar dados como cestas de compras e taxas de retorno aos estímulos de marketing com informações disponíveis em redes sociais e reviews das compras anteriores que foram compartilhados pelos clientes. Assim, empresas varejistas devem sofisticar suas tradicionais ferramentas, softwares e sistemas de gestão de relacionamento com os clientes para que acomodem o cruzamento desses dados.

Em seguida, devem aplicar modelos de análise específicos para gerar insights quanto ao potencial e à probabilidade de compra e retenção por cliente, por exemplo, e às melhorias nos critérios de segmentação de clientes. Os chamados modelos de atribuição são uma alternativa crescentemente considerada no contexto omnichannel. Esses modelos estatísticos envolvem o uso de técnicas sofisticadas de análise de dados para alocar o peso de cada ação do consumidor em relação a cada ponto de contato (online e offline) durante a jornada de compras. Permitem considerar a importância 


\section{EVOLUÇÃO DO USO DE DADOS NO VAREJO}

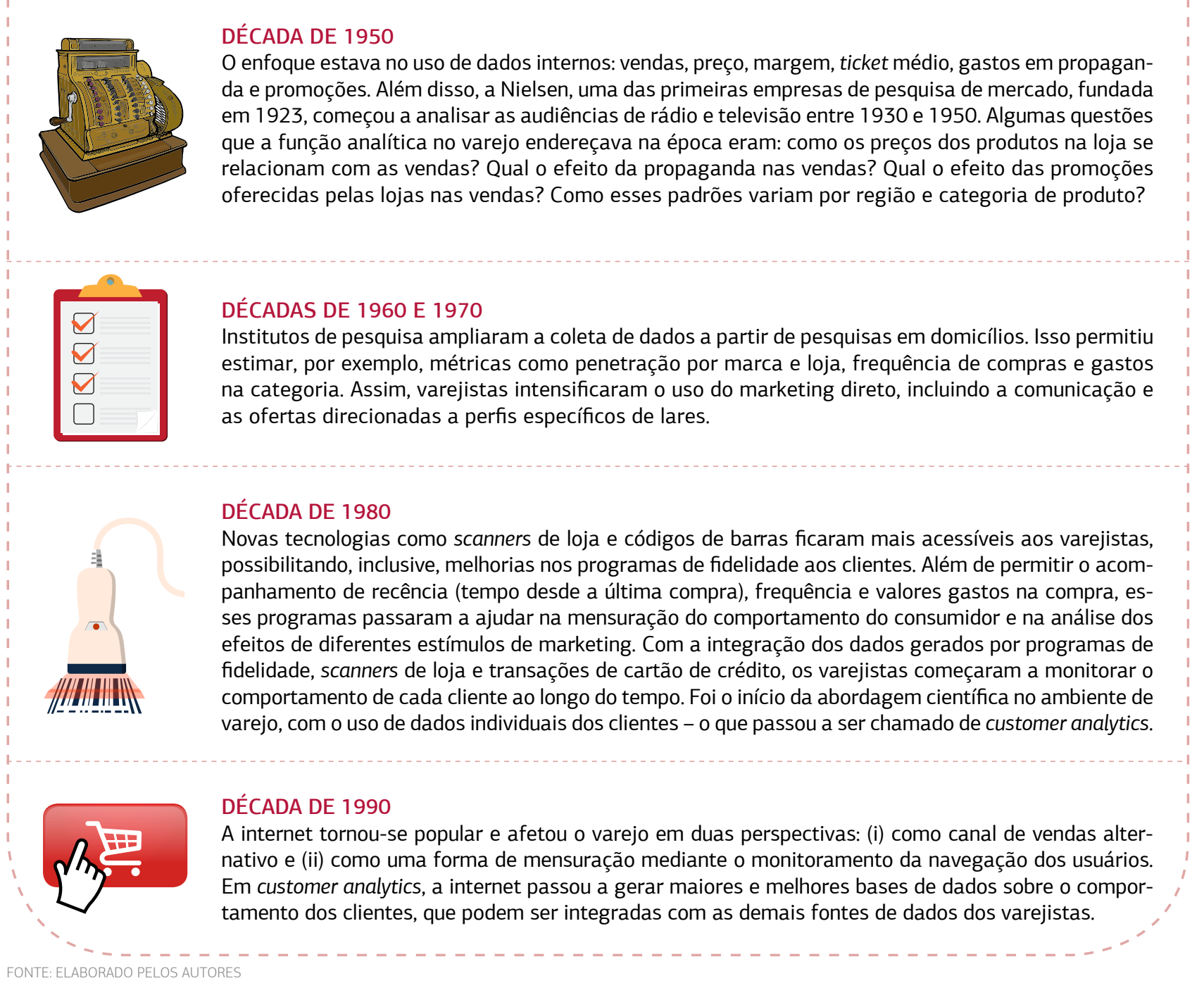

dos pontos de contato, um a um, na conversão de vendas, orientando ações e recursos nos diferentes canais.

Para viabilizar esses modelos, o ideal é usar programas de fidelidade e sistemas de Customer Relationship Management (CRM), que gerenciam processos de seleção, aquisição e retenção de clientes. São alternativas que funcionam desde a coleta e organização dos dados até o uso das informações para personalizar ações e atribuí-las por ponto de contato.

O exemplo da rede de lojas de cosméticos Sephora revela como todos esses aspectos podem agir de forma coordenada. A varejista oferece aos consumidores o seu aplicativo para smartphones (Sephora To Go) e um programa de fidelidade (Beauty Inside Reward). Ambos se integram com sistemas de geolocalização. Assim, a Sephora pode enviar mensagens de ofertas aos membros do seu programa de fidelidade quando estão próximos das lojas, baseando-se em suas preferências, histórico de compras e modo de interação com as lojas física e virtual. Essas ações sincronizadas acabam por gerar possibilidades de maiores taxas de conversão e engajamento com a marca.

Hoje, os consumidores desejam uma experiência consistente entre os múltiplos pontos de contato em suas interações com as empresas. O desenvolvimento da capacidade analítica para o uso de dados pode identificar oportunidades que os varejistas não encontrariam de outra maneira.

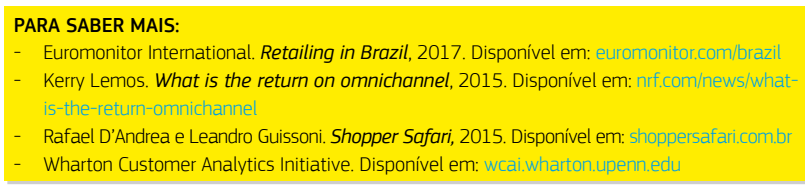

LEANDRO ANGOTTI GUISSONI > Professor da FGV EAESP > leandro.guissoni@fgv.br 